\title{
DEVELOPMENT AND VALIDATION OF STABILITY INDICATING HPTLC METHOD FOR ESTIMATION OF SWERTIAMARIN IN BULK AND DOSAGE FORM
}

\author{
H. PADH, S. PARMAR* ${ }^{*}$, B. PATEL \\ Department of Pharmaceutical Sciences, Sardar Patel University, Vallabh Vidyanagar 388120, India \\ Email: shraddhajparmar@gmail.com
}

Received: 24 Aug 2016, Revised and Accepted: 10 Oct 2017

\begin{abstract}
Objective: In the present study a novel stability-indicating high-performance thin-layer chromatography (HPTLC) method for quantitative determination of Swertiamarin (SW) in bulk drug and formulation has been developed and validated as per ICH guideline Q2 (R1) for global acceptance of standardized herbal formulations.
\end{abstract}

Methods: HPTLC method is developed and validated using solvent ethyl acetate: ethanol: chloroform (3:2.5:4.5 v/v/v) ( $\mathrm{R}_{\mathrm{f}}$ of $\left.S W 0.65 \pm 0.04\right)$ in the absorbance mode at $243 \mathrm{~nm}$. Various forced degradation conditions were used to check degradation of drug.

Results: The method showed a good linear relationship $\left(r^{2}=0.9990\right)$ in the concentration range 200-700 ng per spot. It was found to be linear, accurate, precise and specific.

Conclusion: It can be applied for quality control as well as for stability testing of different dosage forms containing swertiamarin. The developed method is validated as per ICH guideline Q2(R1) for global acceptance of standardized herbal formulations.

Keywords: Swertiamarin, Stability-indicating HPTLC method, ICH guidelines, Quality control

(C) 2017 The Authors. Published by Innovare Academic Sciences Pvt Ltd. This is an open access article under the CC BY license (http://creativecommons.org/licenses/by/4.0/) DOI: http://dx.doi.org/10.22159/ijap.2017v9i6.22214

\section{INTRODUCTION}

Herbal medicinal technology is used for exploring medicinal plant materials as medicines, where standardization and quality control with proper integration of modern scientific techniques and traditional knowledge is important. The chromatographic techniques and marker compounds are used to standardize herbal formulations [1].

The stability indicating assays are important to determine the shelf life of the products. It also helps to determine the storage conditions by knowing the process of degradation. It is carried out by performing forced degradation studies. These types of studies using sophisticated techniques are important for global acceptance of herbal products [2].

It is revealed from the literature survey that aqueous extract of $E$. Littorale produces an anti-diabetic effect in type 2 diabetic rats. Based on activity guided phytopharmacological studies sw was reported to be one of the major active phytochemicals. Further studies showed that E. littorale significantly decreases both cholesterol and triglyceride level. Direct studies at molecular studies with sw revealed that up-regulates PPARY gene expression in 3T3L1 cells. There are some reports on the application of spectrophotometry, spectrofluorimetry, thin layer chromatography, liquid chromatography-mass spectrometry (LC-MS) and highperformance liquid chromatography (HPLC) methods. ICH guidelines have given guidance for the estimation of degradation during storage. There is no stability indication method available for analysis for herbal formulations containing swertiamarin to detect degradation, Hence, it was considered worthwhile to develop precise, cost-effective and stability indicating HPTLC method for determination of SW in bulk drug and dosage form. The HPTLC analytical methods are advantageous over other analytical methods for analysis of botanicals, plant-derived drugs and biomarkers. Several stability-indicating HPTLC methods have been published and being utilized for plant origin biomarkers like curcumin and forskolin. The method developed in the present investigation was validated as per the International conference on harmonization (ICH) guideline (ICH, 2005). The drug was analyzed under different stress conditions to explain the inherent stability characteristics of the active substance and to develop the validated stability-indicating HPTLC assay method (ICH, Q2 (R1) [3-10].

\section{MATERIALS AND METHODS}

\section{Chemicals and reagents}

Methanol, acetonitrile, chloroform, toluene, ethyl acetate, sodium hydroxide, hydrogen peroxide and hydrochloric acid of AR grade were purchased from astron, Ahmedabad. The reference standard of SW is purchased from sigma Aldrich.

\section{Chromatographic conditions}

Stationary phase was precoated silica gel $\mathrm{G}_{00} \mathrm{~F}_{254}$ aluminum sheets $10 \times 10 \mathrm{~cm}^{2}$, layer thickness $0.2 \mathrm{~mm}$. activated TLC plates by prewashing with methanol and activated in the oven at $50{ }^{\circ} \mathrm{C}$ for 5 minutes. The optimized mobile phase was ethyl acetate: ethanol: chloroform $(3: 2.5: 4.5 \mathrm{v} / \mathrm{v} / \mathrm{v})$. Chamber saturation time was 30 minute at ambient temperature and migration distance was $75 \mathrm{~mm}$. The detection was done at $243 \mathrm{~nm}$.

\section{Preparation of solutions}

\section{Preparation of SW standard stock solution $(1000 \mu \mathrm{g} / \mathrm{ml})$}

Accurately weighed $10 \mathrm{mg}$ of SW was transferred into $10 \mathrm{ml}$ volumetric flask, dissolved and diluted up to the mark with methanol to get stock solution having concentration $1000 \mu \mathrm{g} / \mathrm{ml}$.

\section{Preparation of working standard solution $(100 \mu \mathrm{g} / \mathrm{ml})$}

$1 \mathrm{ml}$ of a standard stock solution of SW was transferred to $10 \mathrm{ml}$ volumetric flask and diluted to up to the mark with methanol to get working standard solution having $100 \mu \mathrm{g} / \mathrm{ml}$.

\section{Preparation of solution for calibration curve}

To obtain a calibration curve, working standard solutions ranging from $2,3.5,5,6.5,8,10 \mu \mathrm{l}$ was applied by hamilton syringe with the help of linomat $V$ applicator on TLC plate having concentration 200-1000 ng/ $\mu \mathrm{l}$.

\section{Preparation of sample solution of SW}

20 mamejava pills were weighed and triturated. $5 \mathrm{gm}$ of powdered sample was weighed and transferred to $100 \mathrm{ml}$ volumetric flask containing $25 \mathrm{ml}$ water, sonicated for $20 \mathrm{~min}$ and diluted to mark with ethanol to obtain $5 \mathrm{mg} / \mathrm{ml}$ extract solution. The resulting solution was filtered using whatman filter paper. From the above 
solution, $1 \mathrm{ml}$ was transferred into $10 \mathrm{ml}$ volumetric flask and diluted to mark with the same solvent. So, resultant solution $12 \mu \mathrm{l}$ was injected and amount of SW is calculated in $\% \mathrm{w} / \mathrm{w}$.

\section{Preparation of sample solution from extract}

$1 \mathrm{gm}$ of powdered sample was weighed and transferred to $100 \mathrm{ml}$ volumetric flask containing $25 \mathrm{ml}$ ethanol, sonicated for $20 \mathrm{~min}$ and diluted to mark with ethanol to obtain $1 \mathrm{mg} / \mathrm{ml}$ extract solution. The resulting solution was filtered using whatman filter paper. From the above solution, $1 \mathrm{ml}$ was transferred into $12 \mathrm{ml}$ volumetric flask and diluted to mark with the same solvent. So, resultant solution $8 \mu \mathrm{l}$ was injected and amount of SW is calculated in $\% \mathrm{w} / \mathrm{w}$.

\section{Forced degradation studies}

Stress studies were carried out under the acidic, basic, thermal and oxidation conditions as mentioned in ICH Q1A (R2)

\section{Preparation of standard stock solution for forced degradation studies}

Accurately weighed $10 \mathrm{mg}$ of $\mathrm{SW}$ transferred to $10 \mathrm{ml}$ volumetric flask and diluted up to the mark with methanol to produce $1000 \mu \mathrm{g} / \mathrm{ml}$.

\section{Preparation of control}

$2.5 \mathrm{ml}$ aliquot of the standard stock solution was transferred to $25 \mathrm{~m}$ volumetric flask and diluted up to the mark with methanol to produce a mixture of $100 \mu \mathrm{g} / \mathrm{ml}$ of SW which was used as a control. $4 \mu \mathrm{l}$ of resultant solution of SW (400ng/ $\mu \mathrm{l})$ was applied on TLC plate and developed and scanned as per optimized chromatographic conditions.

\section{Degradation under acid catalyzed hydrolytic condition}

$2.5 \mathrm{ml}$ of a standard stock solution of SW was mixed with $1 \mathrm{ml}$ of $2 \mathrm{~N}$ $\mathrm{HCl}$. The solution was diluted to $25 \mathrm{ml}$ with methanol and the solution was refluxed for 1 hour. It was allowed to cool down. It was neutralized with $0.1 \mathrm{~N}$ sodium hydroxide. $4 \mu \mathrm{l}$ of resultant solution of SW (400ng/ $\mu \mathrm{l})$ was applied on TLC plate and developed and scanned as per optimized chromatographic conditions.

\section{Degradation under alkali catalysed hydrolytic condition}

$2.5 \mathrm{ml}$ of a standard stock solution of SW was mixed with $1 \mathrm{ml}$ of $1 \mathrm{~N}$ $\mathrm{NaOH}$. The solution was diluted to $10 \mathrm{ml}$ with methanol and kept for refluxed for $30 \mathrm{~min}$. It was neutralized using $0.1 \mathrm{~N}$ hydrochloric acid. It was allowed to cool down. $4 \mu \mathrm{l}$ of resultant solution of SW (400 $\mathrm{ng} / \mu \mathrm{l}$ ) was applied to TLC plate and developed and scanned as per optimized chromatographic conditions.

\section{Oxidative degradation}

$2.5 \mathrm{ml}$ of a standard stock solution of SW was mixed with $5 \mathrm{ml}$ of $5 \%$ $\mathrm{H}_{2} \mathrm{O}_{2}$. The solution was diluted to $25 \mathrm{ml}$ with methanol and refluxed for 1 hour. $4 \mu \mathrm{l}$ of resultant solution $(400 \mathrm{ng} / \mu \mathrm{l}$ of SW) was applied to TLC plate and developed and scanned as per optimized chromatographic conditions

\section{Thermal degradation}

$2.5 \mathrm{ml}$ aliquot of the standard stock solution was transferred to $25 \mathrm{ml}$ volumetric flask and diluted up to the mark with methanol to produce $25 \mu \mathrm{g} / \mathrm{ml}$. The resulting solution was subjected to $100{ }^{\circ} \mathrm{C}$ for $30 \mathrm{~min} .4 \mu$ of resultant solution ( $400 \mathrm{ng} / \mu \mathrm{l}$ of SW) was applied on TLC plate and developed and scanned as per optimized chromatographic conditions.

\section{Method validation}

\section{Linearity}

2 to $10 \mu \mathrm{l}$ from the working standard solution having $100 \mathrm{mg} / \mu$ concentration of SW was injected 5 times. So, linearity responses for SW were assessed in the concentration range of $200-1000 \mathrm{ng} / \mu \mathrm{l}$ of working standard solution.

\section{Precision}

\section{Method repeatability}

The precision of the method was checked by repeated scanning and measuring the area of SW $(200-1000 \mathrm{ng} / \mu \mathrm{l})$ solutions $(\mathrm{n}=5)$ without changing the parameters

\section{Instrument repeatability}

The precision of the instrument was checked by spotting $5 \mu \mathrm{l}(500$ $\mathrm{ng} / \mu \mathrm{l}$ ) of standard solution six times on a TLC plate, followed by the development of plate and recording the peak area for six spots.

\section{A) Intra-day precision}

The intra-day precision of the proposed method was determined by analysis of corresponding responses in triplicate on the same day for 3 different concentrations of a standard solution of SW (500, 650 and $800 \mathrm{ng} / \mu \mathrm{l}$ )

\section{B) Inter-day precision}

The inter-day precisions of the proposed method were determined by analysis of corresponding responses in triplicate on 3 different days over a period of $1 \mathrm{w}$ for 3 different concentrations of a standard solution of SW $(500,650$ and $800 \mathrm{ng} / \mu \mathrm{l})$. Results were reported in terms of $\%$ RSD.

\section{Accuracy}

The method was studied for accuracy by calculating recovery of SW by the standard addition method. Known amounts of standard solutions of SW (80,100 and $120 \%)$ were added to pre quantified separate sample solutions of SW. Each solution was determined in triplicates and recovery was calculated by calibration curve or regression equation.

\section{Sensitivity}

The sensitivity of measurement of SW by the use of proposed method was estimated in terms of Limit of Detection (LOD) and Limit of Quantitation (LOQ). The LOD and LOQ were calculated by the standard formula.

\section{Specificity}

The specificity of an analytical method is the ability to measure accurately an analyte in presence of interferences like synthetic precursor, excipients, degradants or matrix component. The purity of spectra was determined at three different levels, at starting, middle and end. Correlation between the spectra of standard and spectra of the drug in sample track was considered for determination of peak purity. The specificity was also determined by checking whether the sample matrix, solvent or mobile phase interfered in the analysis.

\section{RESULTS AND DISCUSSION}

Chawla $\mathrm{R}$ et al. showed rapid schematic representation for the holistic approach needed for standardized herbal medicines for the management of diabetes [2]. The use of stability indicating HPTLC analytical method is one of the thoughtful approaches to achieve globally standardized herbal medicines.

\section{Selection of detection wavelength}

The sensitivity of HPTLC method with UV detection depends upon the proper selection of detection wavelength. An ideal wavelength was the one that gives good response for the drug to be detected. The TLC plate was scanned between 200-400 nm. SW showed maximum absorption at $243 \mathrm{~nm}$. Thus it was selected as detection wavelength for HPTLC analysis. Fig. 1 showed the UV spectra for SW in methanol.

\section{Mobile phase optimization}

The solvent system was developed and optimized using trial and error method. Vishwakarma SL. et al. has developed the HPTLC method for analysis of commercial formulation containing Swertiamarin which suggested the use of ethyl acetate, water, methanol can be used for separation of Swertiamarin. [3] Various proportions of different solvents were tried to get a resolution of the compound. The optimized mobile phase was ethyl acetate: ethanol: chloroform (3:2.5:4.5 v/v/v). The optimized mobile phase could resolve the compound and the band obtained was compact too. Various mobile phases were tried which are listed in table 1 below: 


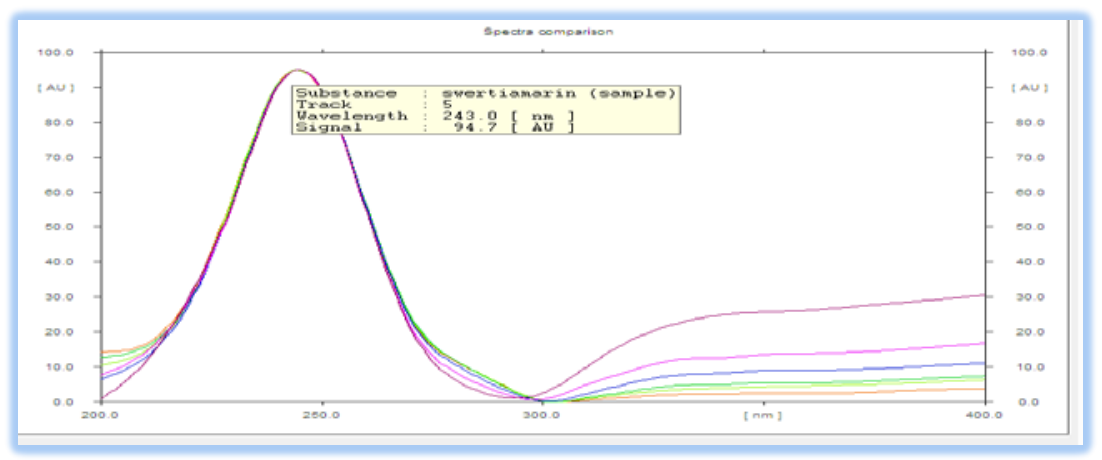

Fig. 1: Wavelength selection for SW

Table 1: Optimization of mobile phase

\begin{tabular}{llll}
\hline S. No. & Mobile phase & Ratio $(\mathbf{v} / \mathbf{v} / \mathbf{v})$ & Remark \\
\hline 1 & ethyl acetate: methanol: water & $8: 1.5: 0.5$ & Unresolved peak \\
2 & ethyl acetate: methanol: chloroform & $5: 1: 4$ & Unresolved peak in acid degradation \\
3 & ethyl acetate: ethanol: toluene & $5: 1.5: 3.5$ & Peak tailing was observed \\
4 & ethyl acetate: ethanol: chloroform & $5: 1: 4$ & Good shape peak was obtained with peak purity \\
\hline
\end{tabular}

$\mathrm{v} / \mathrm{v} / \mathrm{v}=$ ratio in volume

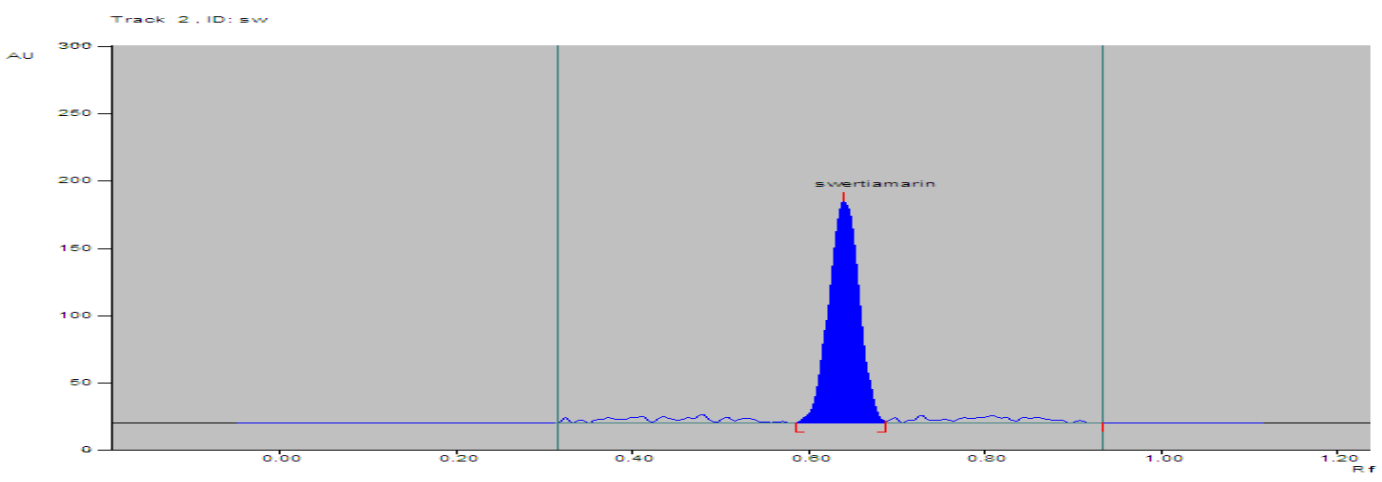

Fig. 2: Standard chromatograph of SW $(450 \mathrm{ng} / \mu \mathrm{l})$

Results from various stress condition for standard SW are shown in table 2 below: Forced degradation shows that SW is most degraded by alkali conditions. It is quite stable with thermal stress.

Table 2: Results of degradation

\begin{tabular}{ll}
\hline Stress condition & \% degradants formed \\
\hline Alkali & $34.55 \%$ \\
Acidic & $23.45 \%$ \\
Oxidative & $31.18 \%$ \\
Thermal degradation & $17.99 \%$ \\
\hline
\end{tabular}

\section{Method validation}

\section{Linearity}

Linearity responses for SW were assessed in the concentration range of $200-1000 \mathrm{ng} / \mu \mathrm{l}$ of working standard solutions. Table 3 shows the data of calibration curve and fig. 3 shows the calibration curve $(200-700 \mathrm{ng} / \mu \mathrm{l})$. The linear equation for the calibration plot was $y=5.573 x+1619$ with correlation coefficient $r^{2} 0.9990$. Fig. no 4 shows 3D densitogram for SW. The value of correlation coefficient $r^{2}$ 0.9990 suggests good linearity.

For all concentration levels of the calibration curve, \% RSD is less than 2 which is an acceptable limit as per ICH guideline Q2 (R1).

Table 3: Result of calibration curve for SW

\begin{tabular}{lll}
\hline Concentration $(\mathbf{n g} / \boldsymbol{\mu l})$ & Area $(\mathbf{A U})$ & \% RSD \\
\hline 200 & $2689 \pm 41.93$ & 1.56 \\
350 & $3601.83 \pm 43.43$ & 1.21 \\
500 & $4455.50 \pm 82.79$ & 1.86 \\
850 & $5201.17 \pm 71.19$ & 1.37 \\
1000 & $6105.50 \pm 79.59$ & 1.30 \\
\hline
\end{tabular}

$*=(n=5)$, Area are presented as mean \pm SD \% RSD $=\%$ relative standard deviation 


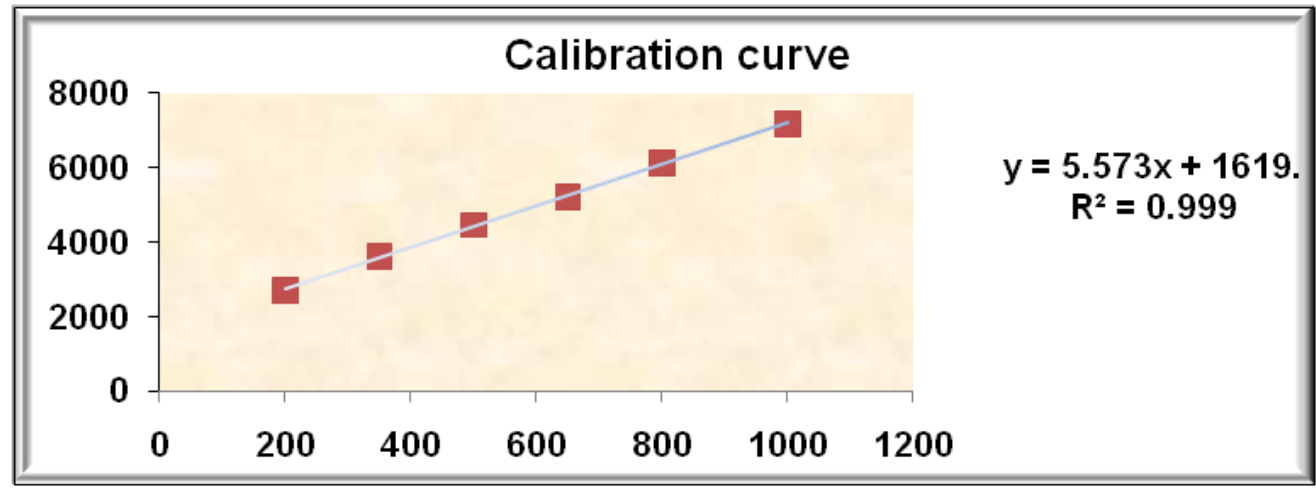

Fig. 3: Calibration curve of SW (200-1000ng/ $\mu \mathrm{l})$

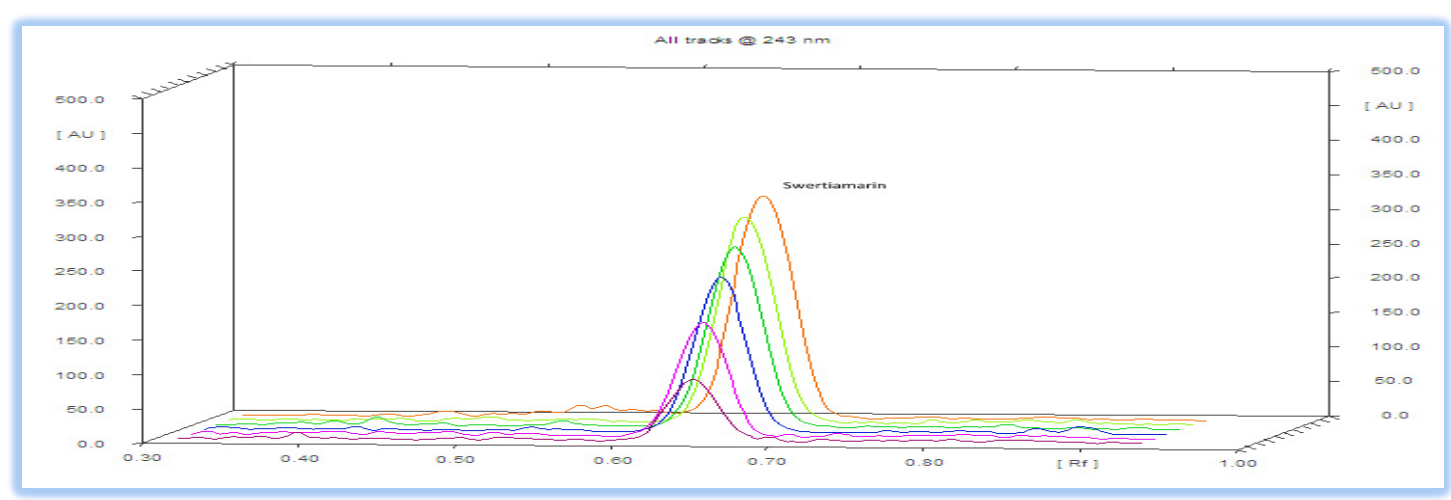

Fig. 4: 3D chromatograph of developed TLC plate of SW (200-1000ng/ $\mu \mathrm{l})$

\section{Precision}

\section{Method repeatability}

The \% RSD for peak area value of SW was found to be ranging between 0.87 to $1.49 \%$, as given in table 4 .

\section{Instrument repeatability}

The \% RSD for peak area value of SW was found to be 1.47 , as given in table 4 .

\section{a) Intra-day precision}

It was expressed as relative standard deviation (RSD \%). The \%R. SD values for the intra-day precision study were between 0.89 to $1.60 \%$. The $\%$ RSD value (table no 4 ) was $<2.0 \%$, confirming that the method was sufficiently precise as per ICH guidelines.

\section{b) Inter-day precision}

The \% RSD value for the inter-day study was found to be between 1.22 to $1.84 \%$ which is shown in table no 4 indicated the method was precise.

Table 4: Intra-day, Inter-day method and instrument repeatability study of SW

\begin{tabular}{|c|c|c|c|c|}
\hline Concentration $(\mathrm{ng} / \mu \mathrm{l})$ & Intraday precision * \% RSD & Inter day precision $* \%$ RSD & Concentration $(\mathrm{ng} / \mu \mathrm{l})$ & \% RSD ** \\
\hline \multirow[t]{2}{*}{500} & 1.60 & 1.71 & 200 & 1.49 \\
\hline & & & 350 & 1.59 \\
\hline \multirow[t]{2}{*}{650} & 0.89 & 1.84 & 500 & 0.47 \\
\hline & & & 650 & 0.87 \\
\hline \multirow[t]{2}{*}{800} & 0.97 & 1.22 & 800 & 0.99 \\
\hline & & & 1000 & 1.09 \\
\hline
\end{tabular}

$*^{*}=(\mathrm{n}=3),{ }^{*}=(\mathrm{n}=5), \% \mathrm{RSD}=\%$ Relative standard deviation

Table 5: Determination of accuracy for SW

\begin{tabular}{|c|c|c|c|c|c|c|}
\hline Level & $\begin{array}{l}\text { Concentration of } \\
\text { sample taken } \\
\mathrm{ng} / \mu \mathrm{l}\end{array}$ & $\begin{array}{l}\text { Concentration of } \\
\text { standard added } \\
\mathrm{ng} / \mu \mathrm{l}\end{array}$ & $\begin{array}{l}\text { Total standard } \\
\mathrm{ng} / \mu \mathrm{l}\end{array}$ & $\begin{array}{l}\text { Mean total } \\
\text { concentration } \\
\text { obtained* } \mathrm{ng} / \mu \mathrm{l}\end{array}$ & $\begin{array}{l}\text { Average assay } \\
\text { (\%) recovery }\end{array}$ & $\begin{array}{l}\text { Assay } \\
\text { \% RSD }\end{array}$ \\
\hline Level 0 & 450 & 0 & 450 & $445+1$ & $98.89+0.22$ & 0.22 \\
\hline Level I (80\%) & 450 & 360 & 810 & $798.67+2.51$ & $98.60+0.31$ & 0.31 \\
\hline Level II (100\%) & 450 & 450 & 900 & $889.33+6.11$ & $98.81+0.67$ & 0.68 \\
\hline Level III (120\%) & 450 & 540 & 990 & $982.67+2.51$ & $99.26+0.25$ & 0.25 \\
\hline
\end{tabular}

$*=(n=3)$, Results are presented as mean \pm SD \% RSD $=\%$ relative standard deviation 


\section{Accuracy}

The amount of drug was calculated by employing corresponding calibration curve equations. The recovery was found to be between $98.60 \%$ to $99.26 \%$ (table 5). The closeness of the result nearly to $100 \%$ assured the accuracy of the developed method.

\section{Sensitivity}

Based on the standard deviation of the response and the slope, the values obtained are $32.22 \mathrm{ng} / \mu \mathrm{l}$ and $134.11 \mathrm{ng} / \mu \mathrm{l}$ respectively for LOD and LOQ.

\section{Specificity}

The peak purity of SW was assessed by comparing their respective spectra at peak start, apex and peak end positions of the spot i.e., $r$ $(\mathrm{s}, \mathrm{m})=0.9877$ and $\mathrm{r}(\mathrm{m}, \mathrm{e})=0.9990$. A good match was obtained between standard and sample spectra of SW which suggest that the developed method is specific.

\section{Analysis of SW in marketed formulation}

Table 6 shows the $\% \mathrm{w} / \mathrm{w}$ of SW in marketed preparation which suggests the quality of the products.

Table 6: Assay result of formulation and extract

\begin{tabular}{ll}
\hline Formulation & Avg. amt. recovered* \% w/w \\
\hline Mamejava pill $250 \mathrm{mg}$ & $9.94 \%$ \\
Marketed extract & $11.12 \%$ \\
\hline
\end{tabular}

$*=(n=3)$, Avg. Amt. = Average amount, $\% \mathrm{w} / \mathrm{w}=\%$ weight by weight

\section{Summary}

The HPTLC method for determination of SW was developed and validated. The results for each validation parameters confirmed linearity, accuracy, precision and selectivity of the developed analytical method as per ICH guidelines. The method showed good linearity over the selected linearity range. The summary validation parameters for the developed analytical method are shown in table 7.

Table 7: Summary of validation parameter

\begin{tabular}{ll}
\hline Parameters & HPTLC method \\
\hline Linearity $(\mathrm{ng} / \mu \mathrm{l})^{*}$ & $200-1000$ \\
LOD $(\mathrm{ng} / \mu \mathrm{l})$ & 32.23 \\
$\mathrm{LOQ}(\mathrm{ng} / \mu \mathrm{l})$ & 134.11 \\
$\%$ Recovery & $99.26 \%-98.60 \%$ \\
Repeatability (\%RSD) ${ }^{*}$ & $0.87 \%$ \\
Precision (\%RSD) & \\
Inter-day & 0.89 to $1.60 \%$ \\
Intra-day & 1.22 to $1.84 \%$ \\
\hline
\end{tabular}

$\% \mathrm{RSD}=\%$ relative standard deviation, ${ }^{*}=(\mathrm{n}=5),{ }^{* *}=(\mathrm{n}=3)$

\section{CONCLUSION}

The developed method is validated as per ICH guideline Q2 (R1) for global acceptance of standardized herbal formulations. The method showed linearity in the concentration range of $200-1000 \mathrm{ng} / \mu \mathrm{l}$ with a coefficient of correlation, $\mathrm{r}^{2}=0.9990$ at $243 \mathrm{~nm}$. The result of the analysis by the proposed method was found to be highly reproducible and reliable. So, the developed HPTLC method is simple, precise and accurate and can be used for determination of SW in pharmaceutical dosage forms. Degradation study is a requirement of ICH guidelines. Here developed method can be used to detect the degradation of swertiamarin during storage. The method can be applicable for routine analysis of SW as per ICH guidelines in quality control lab.

Acknowledgment: The author's work would like to acknowledge Sardar Patel University for providing research seed grant and facilities for this research work.

\section{CONFLICT OF INTERESTS}

Declared none

\section{REFERENCES}

1. Sharma AK, Gaurav SS, Balkrishna A. A rapid and simple scheme for the standardization of polyherbal drugs. Int J Green Pharm 2009;3:134-40.

2. Chawla R. Evidence-based herbal drug standardization approach in coping with challenges of holistic management of diabetes: a dreadful lifestyle disorder of $21^{\text {st }}$ century. J Diabetes Metab Disord 2013;12:35.

3. Vishwakarma SL. A sensitive HPTLC method for estimatin of swertiamarin in Enicostemma littorale blume. J Pharm Chem 2004;17:128-31.

4. Mani R, Kunchu K, Pallab KH. Role of herbal plants in the diabetes mellitus therapy: an overview. Int J Appl Pharm 2014;6:1-3.

5. Shapiro K, Gong WC. Natural products used for diabetes. J Am Pharm Assoc 2002;42:217-26.

6. Bhatt JA. Development and validation of analytical method for estimation of swertiamarin in a marketed preparation containing Enicostemma littrale. World J Pharm Pharm Sci 2016;5:1467-78.

7. Ahamad J, Amin S, Mir SR. Development and validation of HPLC-UV method for estimation of swertiamarin in Enicostemma littorale. J Pharm BioSci 2014;9:1467-78.

8. Alam P. A new HPTLC densitometric method for analysis of swertiamarin in E. Littorale and commercial formulations. Nat Pro Res 2011;25:17-25

9. Lu CM, Lin LC, Tsai TH. Determination and pharmacokinetic study of gentiopicroside, geniposide, baicalin and swertiamarin in Chinese herbal formulae after oral administration in rats by LC-MS/MS. Molecules 2014;19:21560-78.

10. Li HL. Determination of the pharmacokinetic and tissue distributions of swertiamarin in rats by LCMS. Thieme E J 2012;6:138-44 